\title{
Contemporary communication conduit among exemplar school principals in Malaysian schools
}

\author{
Emelia Fantoza Saraih', Su Luan Wong ${ }^{2^{*}} \mathbb{D}$, Soaib Asimiran ${ }^{1}$ and Mas Nida Md. Khambari ${ }^{3}$
}

\author{
${ }^{*}$ Correspondence: \\ suluan@upm.edu.my \\ ${ }^{2}$ Department of Science \\ and Technical Education, \\ Faculty of Educational \\ Studies, Universiti Putra \\ Malaysia, 43400 UPM \\ Serdang, Selangor, Malaysia \\ Full list of author information \\ is available at the end of the \\ article
}

\begin{abstract}
Digital Leadership is relatively a new field of leadership study which focuses on leveraging the technology and Internet in support of one's leadership practice. Currently, very little is known how Malaysian school principals practice Digital Leadership particularly in support of their communication practice. Therefore, this qualitative study was undertaken with the aim of understanding Digital Leadership among principals from four High Performing Schools (HPS) in Malaysia. Semi structured interviews were employed involving four exemplar school principals as the main respondents and 12 school staff as secondary respondents to the study. Findings of the study indicate that social media have become the contemporary communication conduit among exemplar Malaysian school principals and this medium has become more prominent than face-to-face interaction. Findings have also suggested that it may have a positive relation with job performance and productivity. The aforesaid findings have meaningful implications for all school principals to better integrate social media in their communication practice within members of the schools and those outside the school, including the stakeholders.
\end{abstract}

Keywords: Leadership, Digital leadership, Communication, Social media

\section{Introduction}

With the current developments in education-innovation and new technologies, the omnipresent nature of technology and its impact on the education system, contemporary research seems to validate the view that a technology-related leadership style that fosters ICT use in schools is deemed favorable (Brown et al., 2016). Thus effective leadership now must include leadership in technology (Brown et al., 2016).

With the advance of technology and Internet proliferation in this digital age, technology is ubiquitous in the workplace and personal space, and people are being more receptive to technology than ever before. Technology, therefore should be reflected in the study of contemporary leadership practice. School principal leadership practice is not fixated on one particular practice but changes depending on the appropriate time, context and situation of the school (Norman \& Hashim, 2016). The trend of including technology into leadership research is a recent development given that digital leadership

The Author(s) 2022. Open Access This article is licensed under a Creative Commons Attribution 4.0 International License, which permits use, sharing, adaptation, distribution and reproduction in any medium or format, as long as you give appropriate credit to the original author(s) and the source, provide a link to the Creative Commons licence, and indicate if changes were made. The images or other third party material in this article are included in the article's Creative Commons licence, unless indicated otherwise in a credit line to the material. If material is not included in the article's Creative Commons licence and your intended use is not permitted by statutory regulation or exceeds the permitted use, you will need to obtain permission directly from the copyright holder. To view a copy of this licence, visit http:// creativecommons.org/licenses/by/4.0/. 
is a relatively new leadership practice that connects leaders with technology (Sheninger, 2014). Leaders must be able to leverage on ICT and technology to support their leadership practice, for instance in their communication practice (Sheninger, 2014).

Sheninger's introduced Seven Pillars of Digital Leadership in Education: (1) Communication; (2) Public Relations; (3) Branding; (4) Professional growth and development; (5) Student engagement and learning; (6) Learning environment and space; and (7) Opportunity which leverages on the technology. According to him, society have become more reliant on technology, it is incumbent upon leaders to harness the power of digital technologies to support school progress. As schools change, leadership must as well; the Seven Pillars of Digital Leadership in Education thus aim to create school cultures that are transparent, relevant, meaningful, engaging, and inspiring.

Realizing the utmost importance of school leadership, the Malaysian Education Blueprint (Preschool to Post-Secondary Education)/(MEB) 2013-2025 has outlined an ambitious endeavor to ensure that there are high-performing leaders in every school to improve the quality of learning in Malaysia (Ministry of Education Malaysia, 2013). The Blueprint requires every principal to complete the National Professional Qualification for Educational Leaders (NPQEL) at Institut Aminuddin Baki (IAB) prior to their appointment so they develop leadership competencies such as ICT and e-learning knowledge and skills. This is in line with the MOE's plan to promote the quality of education through school leadership. ICT skills includes leveraging the technology in support of school principals' communication practice.

This study case was conducted in High Performing Schools (HPS) in Selangor, Malaysia to discover how school principals communicate internally, with teachers, staff, and students in the school, and externally, with parents, the ministry, and alumni outside the school. Four secondary HPSs in Selangor, Malaysia were selected, from which 16 respondents participated in this study. (HPS) status is the most outstanding award given by the MOE for schools with the best performance. There are over 10,000 primary and secondary public schools in Malaysia, of which approximately $14 \%$, or 140, are currently HPSs.

\section{Literature review}

This global and digital age constitutes a technology and media-rich environment with access to abundant information, rapid changes in technology tools, and the ability to collaborate and make individual contributions on an exceptional scale. Principals in the twenty-first century are expected to lead schools that are vastly different from those in the past (Perera et al., 2016). These schools need strategies formulated by school principals, teachers, and parents together to effectively use ICT in teaching and learning.

Leadership is a complex phenomenon which should be seen as an extraordinary process. One should not be called a leader until he or she has developed the capability to take a committed crew on an exceptional voyage (Graen et al., 2010). To advance our knowledge of leadership, it is necessary to understand the origins of leadership research and theory, which spans more than 100 years according to McCleskey (2014) and Avolio (2007). Indeed, leadership is an evolving and expanding conceptualization which places the leader at the center of group activities (Bass \& Stogdill, 1990). 
Technology advancement has introduced numerous tools to educators and learners alike, such that modern digital technologies have increasingly been adapted to the educational setting (Richardson et al., 2013). Leadership makes all the difference in the success or failure of any organization, including schools. Effective technology leadership ensures successful technology implementation (Anthony, 2012) and improves the quality of teaching and learning in schools (Yu \& Prince, 2016). With the growing importance of digital literacy in educational agendas worldwide, there have been more calls for leadership development in digital education (Jameson, 2013; Sheninger, 2014). As these calls increase, various terms have emerged to describe leadership in this field, including e-leadership, EdTech leadership, ICT leadership, technology leadership, virtual leadership, digital leadership, and online leadership (Jameson, 2013).

It is noteworthy that there is no clear definition of digital leadership. Numerous definitions of leadership exist, which are all valuable as they highlight important elements of the leadership process (Graen et al., 2010). As different definitions have different functions that enable theorists to accomplish their diverse objectives (Littlejohn \& Foss, 2010), establishing a single definition of digital leadership that encompasses all its traits has proven to be impossible (Ayub et al., 2014). Further, digital technology is subjective, has unique value, and carries different meanings to different stakeholders (Outvorst et al., 2017).

Nevertheless, studies have attempted to define digital leadership both briefly and in detail. The terms 'digital leadership' and 'technology leadership' have been used interchangeably in these studies (Outvorst et al., 2017; Zhong, 2016). Taken together, the accurate definition of leadership depends on individual interest in a specific aspect of leadership (McCleskey, 2014). Therefore, digital leadership in this study referred to school principals' use of technology as a conduit in their leadership practice. With the increased demand to incorporate ICT in teaching and learning, school principals need a new style of leadership that works well in the digital age. Specifically, school leaders must be able to demonstrate effective use of ICT in their respective social and working contexts as well as advocate, influence, and foster such capabilities among teachers and students in their schools. Hence, digital leadership is the contemporary leadership style that is necessary to leverage the omnipresence of technology.

According to Bass (2000) and Harris (2009), communication is central to leadership including to school principals as they are the school leaders. From the school perspective, efficient communication is about engaging school community and stakeholders in a two-way communication. Ayub et al. (2014) argue that communication is one of the most difficult tasks that leaders need to deliver. It is challenging for leaders to effectively communicate the changes and cascade it down to the members in the organization. Teachers, staff, students, education ministry, parents and communities are all central in school progress. They need to be engaged on school planning and strategy in support of school progress. Therefore school principals need to find ways to effectively communicate with them because it is undeniably an important skill for leaders (Leithwood et al., 2006).

There are many purposes in communication. School principals need to communicate with members in the school including assistant principals, Ketua Panitia (Head of Subject), teachers as well as other school staff. As Ayub et al., (2014) further explain 
that in the organization, communication among colleagues and fellow employees are carried out to disseminate and retrieve information timely and efficiently, coordinate and complete job tasks, for decision making and finally to minimize or solve conflicts in the organization. Technology and Internet proliferation has enabled them to be connected in real time (Sheninger, 2014). Efficient communication can now take place virtually via various social media tools to fulfill the different purpose of communication.

Oral communication is useful to motivate subordinates (McCleskey, 2014) but as time evolves and moves into the digital age, communication can now be transmitted via digital devices to obtain almost instant real time feedback as oppose to the traditional face-to-face interaction. Indeed, communication via social media platforms have become an indispensable tool among CEOs (Men, 2015). Social media users claim it makes them and organization become more productive (Ibrahim, 2015). They strongly propose that leaders must leverage on and fully utilize mobile technology to enable them to work at any place and time. Productivity can be improved with technology because, leaders can give order, distribute and share information 'on-the-go' and contribute to the job performance (Ibrahim, 2015).

It is found that school principals utilized hybrid ways for communication and collaboration with teachers including for formal meetings, group collaboration, trainings, social media, website, online learning, digital teaching, personalized professional development, peers' modeling, digital management and digital data collection (Zhong, 2016). This shows that school principals interact with teachers face-to-face and via social media. Social media have become the new platform for communication since broadband and wireless technology combined with social media such as blogging and social networking provide a vibrant communication in today's digital world (Haythornthwaite \& Kendall, 2010). For example, although Facebook and Twitter were created as tools to communicate socially, they are now being used to share classrooms information (Ribble \& Miller, 2013). These findings support the use of social media as a contemporary conduit in school principal communication practice.

There are various advantages of employing social media tools as communication practices in schools such as increase interactions between school principals and school members, greater transparency with regard to decision-making and stronger connections with stakeholders and fellow educators (Cox \& McLeod, 2014). It is also essential that leaders at all levels within an institution, including middle managers, subject coordinators and heads of department, are involved and connected in their area of responsibility (Lieve et al., 2010). Similarly, Ahlquist (2014) advised that leaders must stay attuned to the emerging social media platform and digital trends and to integrate them into leadership practice. According to them, social media tools are no longer optional but expected.

Schools as living systems are self-organizing networks of communication in which it is important that schools maintain communication with all school staff, districts, and indeed communities in support of school progress (Harris, 2009). Men (2015) found that a responsive communicator will produce favorable employee relational outcomes with the organization, such as trust, mutual control, commitment, and satisfaction. Communication and trust are key factors in unlocking the relationship 
between leadership and team performance and creativity in which leadership influences team outcomes through overall team communication and trust in teammates (Boies et al., 2015). Communication via technology is effective to increase job performance and thus productivity.

\section{Objective of the study}

Given the aforesaid development of digital leadership, a study was conducted to illuminate the practice of communication with regard to digital leadership among exemplar school principals from High Performing Schools (HPS) in Malaysia. The objective of the study is to discover and describe the practices of communication among them. The research question was, therefore: How do school principals communicate internally, with teachers, staff, and students in the school, and externally, with parents, the ministry, and alumni outside the school? The study offers an in-depth understanding of school principals and their use of ICT as a conduit in their leadership practices namely communication. In particular, this article emphasized on how school principals communicate internally, with teachers, staff and students in the school and externally with parents, ministry and alumni outside the school.

\section{Theoretical framework}

The virtual context in which many leaders now operate offers both opportunities and challenges. Hence, the Complexity Theory and Complexity Leadership Theory (CLT) were employed as the theoretical framework of this study. These theories aid in understanding digital leadership as a product of the dynamic interaction and adaptive orientation in a system wherein new phenomena, new properties, and new behaviors emerge, resulting in new patterns that replace existing ones.

Complexity Theory was employed in this study in order to understand the interconnectedness of systemic influences underpinning digital leadership among exemplar school principals. The complexity theory posits that in a complex environment, organizations and systems, emergent properties and behaviors are produced by the combination of a complex adaptive system (CAS) which are multi-dimensional, non-linear, interconnected, far from equilibrium and unpredictable (Mason, 2014). The complex system in its current state will be redirected as a result of its adaptation based on the new components or elements in the complex environment (Mason, 2008). In relation to this study, school environments are indeed complex with multiplayer that have an impact at a multilevel. Adapting to continual change is a key attribute in the digital age for the school leaders. Change is continuous, ICT and technology makes changes more evident. Adapting is an act of survival and evolution in the complex system. In order to survive in the digital age in which ICT and technology is ubiquitous in today's world, school leaders must be able to leverage on ICT and technology as a conduit to leadership practice in particular their communication practice. It will be remiss for the school leaders to ignore ICT and technology because it is now a survival tool for their leadership practice. Without ICT and technology, schools will be left behind to those that celebrate the use of ICT and technology in support of school progress.

The CLT posits that leadership should not only be seen as a position and authority but also as an emergent, interactive dynamic that changes as a result of multi-connected 
relationships in a complex institution (Uhl-Bien et al., 2007). Leadership theories are not ideologies that must be followed rigidly but rather can be applied in part or in whole depending on the context (Wang \& Torrisi-Steele, 2017). In line with the complexity theory and the CLT, the tremendous changes taking place in education systems in terms of ICT and the Internet give rise to digital leadership. New properties with regards to school principals' leadership evolve, adapt, and develop in accordance with the new environment, wherein the use of ICT tools drive and sustain new student outcomes in the digital era. However, the nuances of digital leadership remain largely elusive. It is in this light that the present study attempted to discover and describe the practices of exemplar secondary school principals in Malaysia with digital leadership.

\section{Methodology}

This study utilized a qualitative case study approach in order to discover and describe the practice of communication with regard to digital leadership of exemplar secondary school principals. A case study design will be proper when the aim of the study is to develop an in-depth description and analysis of a particular event, program or activity (Creswell, 2018). Further, a case study design will be appropriate as it "explore a reallife, contemporary bounded-system (a case) over time, through detailed, in-depth data collection involving multiple sources of information (e.g. field observations, interviews, audiovisual material, and documents and reports), and report a case description and case themes" (Creswell, 2018, pp. 96-97). Communication is an important aspect of leadership practice and being given most attention in this study by the researchers.

Merriam and Tisdell (2016) revealed that the success of an interview depends on the interviewer's skill in asking good questions. Therefore, to maintain a standard interview process, an interview protocol was developed by the researcher, comprising information such as the time, date, location, and duration of the interview as well as questions to guide the researcher in the interview process. The interview protocol guided the researcher in obtaining data within the designed scope and prevented unnecessary questions. To ensure and enhance the effectiveness of the interview protocol in answering the research questions, a pilot study was conducted on the PP school principal. The information received from the participant enabled the researcher to evaluate the appropriateness of the questions in terms of word choice and terminology. It was from this pilot interview that the researcher realized the necessity for a bilingual interview protocol, i.e. in Malay and English. In addition to the pilot interview, the interview protocol was also assessed by expert panel member. His feedback and comments were later integrated into the interview protocol.

For data analysis, the researcher started by transcribing the data from the participants' interviews using the 'Write and Listen' software. To make the data more manageable, the researcher reduced the data by applying codes and then categories, which were later collapsed into themes. In this study, the MAXQDA version 18.1 software was used to organize and assign codes to the large dataset. The assignment of categories and themes was done manually by the researcher.

Data analysis of the study began by reviewing participants' information on their leadership practices based on the Seven Pillars of Digital Leadership in Education (Sheninger, 2014), i.e. Communication, Public Relations, Branding, Student Engagement and 
Learning, Professional Growth and Development, Re-thinking The Learning Environment and Spaces, and Discovering Opportunity. This method is in line with Yin's (2011) assertion that since qualitative data is diverse, following the theoretical propositions that led to a study is a suitable strategy in the initial stage of data analysis.

Apart from Sheninger's (2014) model, the researcher also considered new emergent ideas from the participants that arose from their own contexts, comments, and perspectives on using ICT in their leadership practice. This strategy is consistent with Merriam and Tisdell (2016), as they posit that qualitative data analysis is primarily inductive and comparative. By comparing the data against Sheninger's (2014) model and examining new perspectives aside from those in the model, this research utilized an inductive method of data analysis to produce coherent inferences on digital leadership among Malaysian HPS' exemplar school principals.

\section{Participants}

This study utilized purposeful sampling, a technique commonly used in qualitative study for selecting participants with most knowledge related to the study (Patton, 2002). Besides identifying participants with most knowledge on the subject, purposeful sampling technique emphasizes on the importance of participants' availability and willingness to participate in a study (Patton, 2002). Considering these aspect and the intention to discover and describe the practice of communication with regard to digital leadership among exemplar school principals from HPS in Malaysia, this study applied the aforesaid sampling method to gain an in-depth understanding from the participants who are willing to share their experience.

The primary unit of analysis in this study is the school principals. Four school principals from four HPS were chosen as the main respondents in this study. In addition to the main respondents, 12 more individuals were selected as secondary respondents (assistant school principals, teachers and staff). The secondary respondents were critical in the study as they provided further description and clarification with regard to school principals communicate. Their interview provided the evidence in showcasing school principals contemporary communicate practice among them.

The HPS status is the most outstanding award given by the MOE for schools with the best performance. Selangor has the highest number of HPSs in Malaysia, and apart from that, the Internet User Survey 2017 reported that Selangor has the highest percentage of Internet users in Malaysia (Malaysian Communications \& Multimedia Commission, 2017). Therefore, HPSs in Selangor were relevant to this research which centered on the use of ICT as a conduit in school principals' leadership practice.

\section{Profiles of high performing schools}

The High Performing Schools (HPS) status is the most outstanding award given by the MOE for schools with the best performance. There are over 10,000 primary and secondary public schools in Malaysia, of which approximately 14 percent, or 140, are currently HPSs. Schools can apply for the HPS status if they meet three criteria: (1) from the Band 1 category; (2) pass with at least a minimum score in the Annex SBT 2.0 Instrument; and (3) free from financial audit enquiries for the past three years. The HPS application is 
reviewed and approved by a panel called the Jemaah Nazir dan Jaminan Kualiti (JNJK) established by the MOE.

HPSs are certain to have high performing principals, additional funds from the MOE, as well as greater autonomy in school development planning. Having greater autonomy entails additional finances to fund development efforts, which places HPS principals in a better position to integrate ICT in the teaching and learning process compared to nonHPS principals. This subsequently enables the former to create a conducive learning environment that supports student engagement and learning, to provide effective professional growth and development for teachers, to establish networking and branding, and to leverage social media in communication and public relations.

According to the MOE, as of January 2018, 140 schools nationwide were awarded HPS status since 2010. Since Selangor has the highest number of HPSs in Malaysia, this study focused on HPSs in Selangor. Apart from that, the Internet User Survey 2017 reported that Selangor has the highest percentage of Internet users in Malaysia (Malaysian Communications \& Multimedia Commission, 2017). Therefore, HPSs in Selangor were relevant to this research which centered on the use of ICT as a conduit in school principals' leadership practice.

Four HPS were selected in this study in which three are Full Boarding Schools while one school is a Non-Boarding School. The acronyms KS, SG, and SM represent the full boarding schools while SA represents the non-boarding school. Table 1 shows that these schools were established between 18 and 65 years ago. Although their year of establishment varies, the four schools' HPS status duration indicates less difference, ranging from eight to ten years.

\section{Profile of participants}

Table 2 shows the breakdown of the participants' profiles in which sixteen respondents participated from the four HPSs. In this study, four participants were selected from each school, i.e. one school principal, assistant school principal, teacher, and staff member per school. A pseudonym was assigned to each participant and school to ensure they remained anonymous.

The four school principals have over 20 years of working experience either in schools and/or in the education departments. HPSs are certain to have high performing principals, additional funds from the MOE, as well as greater autonomy in school development planning. High performing school principals are the reasonable choice for the study to select them respondents. The HPS school principals have greater autonomy entails additional finances to fund development efforts, which places HPS principals in a better position to integrate ICT in communication process compared to non-HPS principals.

Table 1 Schools profiles

\begin{tabular}{llllc}
\hline$\#$ & School & School type & Years of establishment & HPS status \\
\hline 1 & KS & Full Boarding school & 65 & 10 \\
2 & SM & 31 & 9 \\
3 & SG & 18 & 8 \\
4 & SA & Non-Boarding school & 49 & 10 \\
\hline
\end{tabular}


Table 2 Summary of Participant Profile

\begin{tabular}{|c|c|c|c|c|c|}
\hline$\#$ & School & Participant & Job position & Gender & Age \\
\hline 1 & KS & J & School Principal & Male & 50 \\
\hline 2 & & K & Assistant School Principal & Female & 52 \\
\hline 3 & & L & Teacher & Female & 47 \\
\hline 4 & & M & School Staff & Male & 29 \\
\hline 5 & SA & A & School Principal & Female & 59 \\
\hline 6 & & B & Assistant School Principal & Female & 54 \\
\hline 7 & & C & Teacher & Female & 42 \\
\hline 8 & & $\mathrm{D}$ & School Staff & Male & 38 \\
\hline 9 & SG & $\mathrm{N}$ & School Principal & Female & 50 \\
\hline 10 & & $P$ & Assistant School Principal & Female & 56 \\
\hline 11 & & Q & Teacher & Female & 31 \\
\hline 12 & & R & School Staff & Male & 38 \\
\hline 13 & SM & E & School Principal & Male & 55 \\
\hline 14 & & $\mathrm{~F}$ & Assistant School Principal & Female & 53 \\
\hline 15 & & G & Teacher & Female & 30 \\
\hline 16 & & $\mathrm{H}$ & School Staff & Male & 58 \\
\hline
\end{tabular}

The four assistant school principals have vast experience with over 20 years in teaching. All four teachers who were interviewed in the study had used ICT in the classroom via Frog VLE. Global investments in ICT to improve teaching and learning in schools have been initiated by many governments such as the USA, the UK, and New Zealand (Buabeng-Andoh, 2012). Malaysia is of no exception when it comes to ICT funding for education, evidenced by its Smart Schools and Frog Virtual Learning Environment (VLE) under the MEB 2013-2025. The Frog VLE Project is a cloud-based virtual learning environment that was introduced in schools by the MOE in 2011. Since then, all HPSs have used Frog VLE in support of teaching and learning. However, in June 2019, the Education Ministry stopped the implementation of Frog VLE. During the study period, all the HPS in this study used Frog VLE in support of teaching and learning. Subjects that were taught in the Frog VLE classroom were Arabic Language, English Language and Basic Computer Science.

The four school staff comprised a Lab Assistant, a Chief Clerk and two ICT Technicians. All assistant school principals, teachers and staff were chosen by their respective school principals to participate in this study.

\section{Ethics}

This study did not engage in sensitive issues that invade the personal life of the participants. The findings of the study also do not negatively impact participants' careers, reputations, or incomes. In fact, this study showcased the participants' success as exemplar school principals, which could act as a benchmark for others. Nevertheless, prior to its implementation, the researcher obtained permission from the MOE to conduct the study as it involves schools. Specifically, permission to interview the school principals and to enter the schools for field observations were secured from the MOE, the State Education Department, and the school principals themselves. Their approval was in line with the ethical code of the study. 
The Ethics Committee for Research involving Human Subjects of UPM (JKEUPM) states that approval from the committee is mandatory for a study involving human subjects. Prior to the interview process, this study sought and received the approval of the JKEUPM.

\section{Data collection}

This study on digital leadership was conducted through the qualitative approach because the intent is to discover and describe the current practice of exemplar school principals from Malaysian HPS on their use of ICT as a conduit in communication. Through a qualitative method, a face-to-face interview in particular, an in-depth information on their daily digital leadership practice in particular their communication practice was ascertained and analyzed.

\section{Data analysis}

The researcher started with data transcription from the interview sessions with the participants. Data transcription was done using the Write and Listen software. In order to make the data more manageable, the researcher reduce the data by applying codes and categories to the data. Once the initial set of codes was generated, each transcript was analyzed using the codes. New codes were added whenever new concepts came out. The categories were later collapsed into themes. In this study, MAXQDA version 18.1 was used to organize and assign codes to the large data. Assignment of categories and theme were done manually by the researcher.

The theoretical framework, complexity theory and complexity leadership theory was adopted as the data analysis framework. In relation to this study, school environment are complex, with multiplayer that have an impact at a multilevel. Adapting to continual change is a key attribute in the digital age for the school leaders. Change is continuous, ICT and technology make changes more evident. Data analysis of the study began by reviewing participants' information on their leadership practice based on the seven pillar of digital leadership in Education (Sheninger, 2014) model with respect to communication practice. Seven Pillars of Digital Leadership in Education includes (1) Communication; (2) Public Relations; (3) Branding; (4) Professional growth and development; (5) Student engagement and learning; (6) Learning environment and space; and (7) Opportunity (Sheninger, 2014). Apart from the Sheninger's model, the researchers also looked into new, emergent ideas from the participants that arised from their own context, comments and perspective about using ICT in their leadership practice.

Member check was employed in this study in which participants' feedback and consent of the coding was solicited to ensure it represents their meaning. In addition to that, interview sessions were audio taped to minimize errors and mistakes during the transcribing process with participants' permission.

\section{Results and discussion}

The research question in this study sought to determine school principals' communication practices; how school principals communicate internally, with teachers, staff, and students in the school, and externally, with parents, the ministry, and alumni outside the school. When asked about using technology as a conduit in their internal and external 
communication, all four school principals admitted that they rely on social media as an important medium of communication in today's world. Moving into the digital age, communication in schools can now be transmitted via digital devices. Technology has become the contemporary conduit in their communication practice as a school principal in both internal and external communication. Although face-to-face communication has been noticeably reduced, it still remains as one of the communication channels for school principals. The school principals' communication practice can be described by the Contemporary Communication Practice: WhatsApp and Telegram theme. This theme can be further described through five categories: Preferred medium of communication, Social media is the latest trend, important and a necessity at present and in future, Social media as an effective communication medium, The Systematic Group in WhatsApp and Telegram and Communication occurs all the time categories.

\section{Preferred medium of communication}

The study further finds that the preferred medium of communication via technology by the school principals are WhatsApp and Telegram-two widely used social media platform for communication in Malaysia. All school principals utilize both WhatsApp and Telegram in their daily communication with teachers and staff, and they use them extensively as illustrated by several interviewees in the following interview excerpts:

I use a lot of WhatsApp. [WhatsApp is] Important, there are groups, various groups... We use WhatsApp. We have a group [WhatsApp Group].

- A (School principal, SA School Interview).

So he [school principal] uses a lot of Telegram and WhatsApp...He uses a lot of telegram...If personal, he uses WhatsApp. Usually he [school principal] uses this media [Telegram and WhatsApp], I can say almost, for almost everything. - H (School Staff, SM School Interview).

I use WhatsApp with her [school principal] regularly. But for official matters, she [school principal] will use Telegram, mostly. For direct, personal messages she [school principal] uses WhatsApp. But if it's a formal thing or a bulk message, she [school principal] will use Telegram.

- R (School Staff, SG School Interview).

Every information that will be delivered to all teachers will use Tele Info KS (School Telegram Chat Group).

- K (Assistant School principal, KS School Interview).

Telegram is very handy so we are using Telegram for all.

- L (Teacher, KS School Interview).

The aforesaid excerpts notably represents the preferred choice of medium of communication by school principal when communicating with subordinates in the school.

Some schools have Telegram Groups as the official school group chat but one school prefer WhatsApp Group. SM, SG and KS school chose Telegram as the official Group Chat for their school while SA school chose WhatsApp. In the following interview 
excerpts, respondents C, F, R and M reported on the official Group Chat that they have in their school as follows:

That's the official name for the official WhatsApp group.

- C (Teacher, SA School Interview)

We use Telegram which we call Tele Info SM. We have a dedicated Telegram Group.

- $R$ (School Staff, SG School Interview)

- F (Assistant School principal, SM School Interview)

But for official matters, she (school principal) will use Telegram, mostly.

The official [Group Chat] is Telegram.

- M (School Staff, KS School Interview)

In other cases, school principal differentiates official and non-official communication in the school based on Telegram Group or WhatsApp Group. When Telegram is the official Group Chat for the school, all official matters will be disseminated via Telegram Group Chat and vice versa as described in the following excerpts:

So we have Telegram group for official matters...We have a WhatsApp group and it is more to, like a leisure group... Telegram group for official matters.

- L (Teacher, KS School Interview)

That's the official name for the official WhatsApp group.

- C (Teacher, SA School Interview)

If he [school principal] wants it personal [communication], he uses WhatsApp. Telegram for official use.

- H (School Staff, SM School Interview)

Another example, when a text message is received via a Telegram Group Chat, it is more convenient and practical for the school principal to forward the message via the school Telegram Group Chat rather than the school WhatsApp Group Chat, although members of the school have both Telegram and WhatsApp Group Chat. Participant B confirms that school principals make use of both medium: 'If she (school principal) gets information from Telegram, she will resend [to me] via Telegram. [But] if she (school principal) gets from WhatsApp, she will resend [to me] via WhatsApp.

Overall, these results indicate that school principals make use of both medium to communicate depending on the situation whether it is official or not and what medium is most convenient to them. WhatsApp and Telegram are the preferred medium as it facilitates a responsive communication between school principals and his/her subordinates. The findings are consistent with Men (2015) who explained on the growing number of CEOs in embracing social media in their communication practice because leaders who use social media are more likely to be perceived as responsive communicators. 


\section{Social media is the latest trend, important and a necessity at present and in future}

This study finds that a common views amongst interviewees was that at present, social media are a necessity, important and the latest trend in school principal communication practice. In the following excerpts, interviewees emphasized on the importance of social media for school principal communication practice:

Indeed, this is important (indicating smartphone). Now without this, it's difficult.

- A (School principal, SA School Interview).

For now, it [social media as a communication medium] is very important.

- J (School principal, KS School Interview).

Social media is important. We must use this social media as our convenience in connecting with stakeholders or with parents who are our main clients...That is the latest [communication] channel that we should use.

- E (School principal, SM School Interview).

Now everyone is communicating more via WhatsApp than to communicate face-toface. This the trend.

- B (Assistant School principal, SA School Interview).

Telegram is number one [for communication]. [It is] Very important

- G (Teacher, SM School Interview).

In this era of globalization, if there is no (social media), [one] cannot survive.

- Q (Teacher, SG School Interview).

If we don't have it (WhatsApp or Telegram), it's really difficult...It is a necessity, something that if we do not have, it is difficult to communicate...Nowadays, without a smart phone, without Telegram, no way [can we communicate].

- $R$ (School Staff, SG School Interview).

The aforesaid findings uncover that social media are a necessity, important and the latest trend in school principal communication practice. As one interviewee puts it: '...if there is no (social media), [one] cannot survive.' Social media is deemed as a survival tool in today's communication practice. In other words, communication will not take place without it. As such, WhatsApp and Telegram is contemporary in communication practice among HPS school principals, the newly added element to the school system. School principals are keeping up with the technology and leveraging on it to stay ahead as respondent $\mathrm{N}$ reveals that: 'the reason [for using WhatsApp] is [it is] the current demand. We do not look back [and] we must move forward.'

School principals must be alert and move forward in order to stay relevant because those who are not leveraging on social media are deemed backwards by the participant. In addition to that, respondent B accentuates: 'Now everyone is communicating even more with WhatsApp than to communicate face-to-face. This [is] the trend'. Communicating via WhatsApp and Telegram is a preferred choice because it is the lifestyle, the current practice of today's society. Participants in this study collectively agree that the 
social media is now an important conduit in communication, 'Indeed, this is important (indicating smartphone). Now without this, it's difficult', confirms A, school principal from SA School.

Teachers and staff also leverage on social media to communicate with school principals, their colleagues and other staff in their school as well. In the following interview excerpts, participants R, P and B illustrate the use of social media in their communication practice as a modern lifestyle which defines sophistication and being:

WhatsApp application, Telegram. That's the way we are [communicating] because now it is sophisticated.

- P (Assistant School principal, SG School Interview).

Now everyone is communicating more via WhatsApp than to communicate face-toface. This [is] the trend.

- B (Assistant School principal, SA School Interview).

Because this [using social media in communication], well, we must keep up with the latest technology...For me this is very important for a modern lifestyle right now.

- R (School Staff, SG School Interview).

The following excerpts suggest that social media will be continued to be used in the future because participants perceive it as the fastest medium for communication, and is reflective of their modern lifestyle.

Yes [that school principals will depend on social media]. And in the future, I think this is our next step [in communication]. But this thing [using social media to communicate] is going to be used, the more modern we are, the more we will use [social media to communicate].

- N (School principal, SG School Interview).

I feel that this will be the case [using social media in the future] because this social media is the fastest medium to deliver information.

- F (Assistant School principal, SM School Interview).

Certainly. Of course it [social media] will be used, what more with the advanced software.

- C (Teacher, SA School Interview).

I think he (school principal) will use the media to keep in touch. I believe he will continue to use. Even though when he retires, he will continue to use it.

- H (School Staff, SM School Interview).

Taken together the study finds that social media are a necessity and pertinent in the participants' lives. It is also seen to be the latest trend not only in the school principal communication practice but also for teachers and staff. In addition, the respondents of this study believe that social media will remain as the future communication medium for the school principals. Similarly, Ahlquist (2014) advised that leaders must stay attuned 
to the emerging social media platform and digital trends and to integrate them into leadership practice.

\section{Social media as an effective communication medium}

When asked about the effectiveness of social media as a communication conduit, the participants were unanimous in the views that social media via WhatsApp and Telegram Group Chats is effective because of its benefit to users. The most obvious benefit of communicating via WhatsApp and Telegram is because of its communication speed. It is also convenient to use and highly accessible to its users. The majority of the respondents in this study kept on repeating the word 'it is fast' and 'it is quick' as the major reason for using WhatsApp and Telegram as their preferred communication medium as shown in the following excerpts:

Report can be send very fast. Fast. Quick. The letter is for formality. But information [via social media] will reach first [faster than the letter].

- J (School principal, KS School Interview).

It (social media) is fast. It is instant.

- A (School principal, SA School Interview).

We need to communicate, right? Now everything goes fast. Everything need to be ready by today. Dateline needs to be met, so we have to use WhatsApp or Telegram. [It is] effective because it is fast.

- B (Assistant School principal, SA School Interview).

We can convey information fastest through the sophistication of technology. Social media has become the fastest way to deliver information.

- F (Assistant School principal, SM School Interview).

Using Telegram is very fast. Using any ICT service is very fast, on the dot. For an example, let say if he (School principal) goes for an important meeting outside there, he will immediately text to us, the gist of the meeting... we are not left out. We can straight away take any sort of action, if there is a need immediately. So the message is relayed immediately.

- L (Teacher, KS School Interview).

Firstly, it [social media] is fast. Very fast and quick.

- G (Teacher, SM School Interview).

This thing (Telegram and WhatsApp) facilitates our work, [it is] very fast and quick. - R (School Staff, SG School Interview).

These findings reveal that urgent or immediate messages are best conveyed by WhatsApp and Telegram. These findings suggest that social media via WhatsApp and Telegram are indeed a fast medium today for communication purposes. In addition, when time is of an essence, school principals can rely on WhatsApp and Telegram to 
communicate as interviewee $\mathrm{L}$ expresses: 'message is relayed immediately' making WhatsApp and Telegram an effective communication conduit at present.

Communicating via WhatsApp and Telegram is effective according to participant G: 'we can get a very fast response' from the message that was sent. Not only urgent message can be sent immediately via WhatsApp and Telegram, feedback and responses can be solicited as fast. Communicating via WhatsApp and Telegram is effective because it goes both way, in which the sender and receiver can communicate with each other, and at a very fast pace, almost immediately.

Apart from being fast, communication via WhatsApp and Telegram is effective given its transparency as it is an open communication platform between senders and recipients as illustrated in the following excerpt:

Information is delivered very fast and changes can be made quickly. And the information is accurate. When we are in the group [WhatsApp or Telegram], when information is not right we can make correction quickly. If we were wrong, we correct it. What's important, [it is] open [communication]. Responses must not be limited. - J (School principal, KS School Interview).

According to participant J, communication via WhatsApp and Telegram is effective when school principals can easily remedy incorrect or incomplete information in the group chat. Moreover, being an open platform, in which 'Responses must not be limited', recipients can ask questions, seek advices and make suggestions pertaining to the text messages that they receive. Overall, these results indicate that communication via WhatsApp or Telegram Group Chat proves to be an effective communication conduit for the school principal.

The other benefit is that the earlier information one gets, the better preparation can be made. Interviewee $C$ acknowledges: 'Teachers have been informed earlier so if we get early information, we can be ready earlier. That is why I said it is [social media] effective. At least we already know, no need to wait for the letter [to arrive]. That is why I said it ([WhatsApp/Telegram) is really effective.' One more benefit is that teachers are able to take up the necessary action without any delay according to Interviewee L: 'We can straight away take any sort of action, if there is a need immediately' The findings show that communicating via WhatsApp and Telegram is effective because it is the best way to deliver information and to receive immediate response which facilitates their work. Further benefit of communicating via WhatsApp and Telegram is that it improves productivity where teachers are able to take up the necessary action without delay. As an example of improved productivity, interviewee $C$ concedes: 'For example, if the principal said we will have a meeting, in five minutes we can start the meeting, previously we need [to prepare and send] letters [first].'

Apart from being, probably the fastest medium in communication practice at present, there is another strong reason as to why school principal prefers WhatsApp and Telegram. According to respondent A: '[It is] free. No need to pay [to use WhatsApp and Telegram]. Everybody has this thing [WhatsApp and Telegram], easier [to communicate]'. These two facts; that WhatsApp and Telegram application is actually free of charge to its users and that everybody has them, is a great push and pull factor in adopting WhatsApp and Telegram application in the school principal communication practice. Not only it is 
a fast medium for communication, it allows immediate response and feedback, foster two-way communication between the receiver and sender in an almost instant time, but is also a convenient communication conduit because users do not incur cost.

WhatsApp and Telegram Group Chats are seen as a convenient communication conduit among school principal because they are highly accessible. Given the ubiquity of smartphones as participant L emphasizes: 'Now everyone is hanging on the phone.' 'Hanging on the phone' shows the level of dependency people has towards their smartphones. Further, participants A and $\mathrm{K}$ claim that they carry the smartphones all the time and also frequently checking for new incoming text messages as indicated in the following excerpts.

I think nowadays, it [WhatsApp or Telegram] is the first thing we look at when we wake up. Am I right? Unless it is out of battery. That's another story.

- A (School principal, SA School Interview).

This WhatsApp, like every 5 minutes we need to look at it, what is going on [in the WhatsApp/Telegram group chat]. We are afraid if we missed out on something [important].

- K (Assistant School principal, KS School Interview).

In the aforesaid findings, the study shows that communication between school principal and their subordinates happens all the time. To fulfill this need, WhatsApp and Telegram is a convenient medium for the school principal to communicate because subordinates have them and it is accessible to them most of the time, as participants L, A and $\mathrm{K}$ endorsed.

Further example of WhatsApp and Telegram as an accessible communication conduit is that school principals are able to communicate effectively without being physically present in schools. As one interviewee put it: 'Sometimes he is not always in the office... has a class to attend... has a meeting outside...he's got to use Telegram'. The aforesaid interview with respondent $\mathrm{M}$ explains how WhatsApp and Telegram are a handy conduit for communication as school principal can still be consulted for decision and direction, receives and sends important documents even though he/she is not in the school. Communication via WhatsApp and Telegram permits conversations to be carried out among people regardless of time and location, even where one or both parties are on the move or travelling.

This is the advantage of social media as a communication medium which makes it very effective because the school principals are reachable and accessible beyond school hours and location as seen by their subordinates.

Furthermore, text communication via WhatsApp and Telegram is more efficient because of its clarity. According to respondent L: 'If you are texting, it is very clear instruction on what to do. So the instructions are delivered in a proper manner? Respondent $\mathrm{L}$ in this instance prefers instructions via texting than verbal because written text is more precise and more proper.

'We would always read again [the text via WhatsApp or Telegram]... That's the difference between texting and verbal communication. If it is verbal, we listened once and we forget. But the text, written text [via WhatsApp or Telegram], we will read 
again unless we delete it. [We will] Read again. That is why it [WhatsApp or Telegram] is effective because we will always read it [repetitively].

- P (Assistant School principal, SG School Interview).

Similarly, respondent $\mathrm{P}$ agree communication through text is better than verbal because the message can be read and re-read for clarity as indicated in the aforesaid excerpt.

In a nutshell, the study finds that WhatsApp and Telegram are effective communication medium for school principals because of its speed allows immediate response and feedback. The medium foster instantaneous two-way communication between the receiver and sender, improves clarity and are highly accessible without cost. Thus communication via WhatsApp and Telegram are simply indispensable for the school principals in this study. The findings are consistent with Cox and McLeod (2014) when they listed the many advantages of employing social media tools as communication practice in schools including more immediate and more frequent interactions, greater transparency regarding decision-making, stronger connections and use is an expectation because it is no longer optional. Ayub et al. (2014) argued that one of the most difficult tasks for any leader is to effectively communicate the changes and cascade it down to the members in the organization.

\section{The systematic group in Whatsapp and Telegram}

Another advantage of using WhatsApp and Telegram in communication is the Group Chat feature. These prominent feature contributes significantly to the effectiveness of communicating through the social media platform. The Group Chat is a profound feature because it makes communication via WhatsApp and Telegram a systematic communication medium. There are countless Group Chat in the school as indicated by respondents of the study: 'many groups', 'various groups, 'Yes, so many group now', 'I think I have 50 groups' and 'I guess thousands of groups'.

Although there are countless Group Chat in the school, in general the groups can be divided into two main categories- "official group' and 'unofficial group.' Basically the "official group' is linked with the basic job function of the schools such as administration, academic, co-curriculum activities and student affairs. On the other hand, 'unofficial group' is for personal matters. The following interview excerpt described the two distinct Group Chat in the school as follows.

So we have Telegram group for official matters...We have a WhatsApp group and

it is more to, like a leisure group... Telegram group for official matters.

- L (Teacher, KS School Interview).

If he [school principal] wants it personal [communication], he uses WhatsApp.

Telegram for official use.

- H (School Staff, SM School Interview).

There are numerous 'official group' such as the 'School principal Group', 'English Group', 'Warden Group' and 'School Alumni Group'. Besides these official Group 
Chats, there are also 'unofficial group' in the school. For instance, the 'Lady Teachers Group, 'Shopping Group' and 'Pot Luck Group'.

The WhatsApp and Telegram Groups are effective to encourage a systematic communication practice for school principal. Interviewee $\mathrm{N}$ points out: 'The groups are systematic' and it is restricted by their membership because according to interviewee Q: 'Only relevant teachers will be members of a particular group.' For example, in the Administration Group, the membership is limited to school principal and their Assistant school principal. In the Warden group, the membership is limited to school principal and Warden and a perhaps a few selected teachers who are members. In the English Group, the membership is limited to English Chairman Teacher and all English Teachers as members. All information circulating in this Administration Group, Warden Group or English Group is exclusive for its members only. Those who are not members will not get the information hence confidential information will remain protected.

Interestingly, apart from being systematic, the various WhatsApp and Telegram groups are not static but organic in nature. This is a rather interesting result which has not previously been described. Respondent Q, an Arabic Language teacher from SG School illustrated the organic nature of a typical WhatsApp and Telegram groups in her school in the following interview excerpt:

There are several (WhatsApp or Telegram) groups provided [in the school]. There is one official Telegram group which the school principal created where all teachers and staff are members. There are also smaller groups in which the school principal is working on specific assignments such as SPM Group, PT3 Group and Warden Group. Only relevant teachers will be members of the Group. We also have secretariat Group in conjunction with certain programs. And will be disbanded after the program is completed. In addition, we also have unofficial Groups, typically WhatsApp. Such as the Pot Luck Group, Women's Teachers Group and Shopping Group.

- Q (Teacher, SG School Interview).

Perhaps in the beginning, when the school principals made a decision to adopt social media in their communication practice, they started with a simple one WhatsApp or Telegram group for all. Later on, a few more WhatsApp and Telegram subgroups were created with lesser number of group members which is exclusive based on their mutual responsibility or interest. In this way, social media is organic in the sense that these subgroups can actually be regrouped, merged with another subgroups or de attached from the main group. Some groups are even terminated altogether when the job is completed. These result are also in congruence with Ibrahim's (2015) findings which proposed that school principals to fully utilize mobile technology in order to practice their virtual leadership functions because technology increases the effectiveness of intra-team communication and contribute to the job performance.

The existence of WhatsApp and Telegram Groups in schools enables all school staff including the school principals, assistant school principals, teachers and staff to connect virtually with one another. The findings support those of Lieve et al. (2010) who emphasize that it is essential that leaders at all levels within an institution, including middle managers, subject coordinators and heads of department, are involved in their area of responsibility. A similar result was found from Harris (2009) who notes that schools as 
living systems are self-organizing networks of communication in which it is important that schools maintain communication with all school staff. In this instance, the use of WhatsApp and Telegram with its organic Group Chat features.

The evidence presented in this study has established that social media, specifically WhatsApp and Telegram, is the significant new component or element in the school environment that influences school principals to adapt to and adopt social media, resulting in emergent properties, i.e. digital leadership. These findings are consistent with the complexity theory and the CLT, both of which suggest that a new addition of technology will give rise to new behaviors that feature contemporary skills vital to a system's survival. In this study, WhatsApp and Telegram are important to school principals for their internal and external communication practices because these platforms are fast, efficient, free, highly accessible, systematic, and organic communication tools. It is indeed difficult for school principals to avoid using WhatsApp and Telegram in communicating because they are by far the most contemporary communication practices in this digital age, not only in schools but everywhere else in the world.

The findings are also consistent with the complexity theory's postulation that schools are connected to and interact with each other in many different ways. Accordingly, various platforms exist for school principals to stay connected with teachers, staff, students, parents, ministries, and alumni. Of these, WhatsApp and Telegram have emerged as the contemporary conduit in school principals' communication practice aside from faceto-face communication. In fact, it is apparent that face-to-face meetings with teachers, staff, students, parents, alumni, and ministries remain very much in practice. This was supported by McCleskey (2014), who noted that oral communication is useful to motivate and arouse followers' emotions.

The findings are also in line with Sheninger's Seven Pillars of Digital Leadership in Education: (1) Communication; (2) Public Relations; (3) Branding; (4) Professional growth and development; (5) Student engagement and learning; (6) Learning environment and space; and (7) Opportunity. Communication being the first pillar is considered the upmost important in the Seven Pillars of Digital Leadership in Education as shown in the findings.

The findings of this study have contributed to the understanding and knowledge of digital leadership among HPS school principals. Nevertheless, there is still a need for further research in this area, for much remains to be understood and appreciated about digital leadership. Another aspect that can be improved by future research on digital leadership is the involvement of students, parents, alumni, and the education ministry in upcoming studies. These groups were not interviewed in the current study and their direct involvement in future studies will reveal comprehensive findings about digital leadership from their perspectives.

\section{Conclusion}

Suffice to say, social media in particular WhatsApp and Telegram is the Contemporary Communication play a dominant role in in the contemporary communication practice among school principals. WhatsApp and Telegram is effective for communication because it supports communication at all time, regardless of time and space, it is fast, trendy and sophisticated. WhatsApp and Telegram are effective for communication 
because they support communication regardless of time and location. In addition, both medium are seen to be a fast, trendy and sophisticated communication tool. WhatsApp and Telegram are noticeably an efficient communication conduit that enables leaders to work given its affordances to enhance job performance and productivity. Furthermore, the teachers' and staff members' job performance and productivity seem to improve given their efficient communication method through social media.

It can, therefore, be concluded that exemplar school principals in Malaysia are leveraging on the current social media namely WhatsApp and Telegram as a conduit in support of their communication practice while at the same time teachers and staff members are benefitting in various ways.

For future research, the researchers suggest that the legal implications involving decisions made by school principals via social media should be looked into. Apart from that, future research in similar area should consider interviewing students, parents, alumni and education ministry officer. Their direct involvement in the study will disclose findings about digital leadership from a wide-ranging perspectives. This is an important limitation of the study that should be addressed in future research as this study only interviewed teachers including assistant school principals and staff of the participated schools.

It is noteworthy to mention that in this current study, all teachers including assistant school principals and staff were handpicked by their respective school principals. Perhaps their selection was based on the most available person at the time of study to facilitate the researchers. Secondly, their selection could also be based on individual with most used technology in the school to the school principals' best knowledge and assessment. The findings of the result may be of use to school principals with similar school setting and teachers and staff with similar attributes.

\section{Abbreviations}

HPS: High performing schools; CAS: Complex adaptive system; ICT: Information and communication technology; VLE: Virtual learning environment.

\section{Acknowledgements}

The authors fully acknowledge all participants as well as the Malaysian Education Ministry's contribution in this study.

\section{Authors' contributions}

Emelia Fantoza Saraih was the main author of the paper who conducted the literature review, interviews, and wrote the majority part of the paper. Su Luan Wong finalized the manuscript. All authors offered crucial ideas in conceptualizing the research.

\section{Funding}

Not applicable.

Availability of data and materials

Availability of data and materials upon reasonable requests.

\section{Declarations}

Competing interests

The authors declare that they have no competing interests.

\section{Author details}

${ }^{1}$ Faculty of Educational Studies, Universiti Putra Malaysia, 43400 UPM Serdang, Selangor, Malaysia. ${ }^{2}$ Department of Science and Technical Education, Faculty of Educational Studies, Universiti Putra Malaysia, 43400 UPM Serdang, Selangor, Malaysia. ${ }^{3}$ Department of Foundation of Education, Faculty of Educational Studies, Universiti Putra Malaysia, 43400 UPM Serdang, Selangor, Malaysia. 
Received: 18 November 2020 Accepted: 25 November 2021

Published online: 29 January 2022

\section{References}

Ahlquist, J. (2014). Trending Now : Digital Leadership Education Using Social Media and the Social Change Model. Journal of Leadership Studies, 8(2), 57-60. https://doi.org/10.1002/js.21332

Anthony, A. (2012). Activity theory as a framework for investigating district-classroom system interactions and their influences on technology integration. Journal of Research on Technology in Education, 44(4), 335-356.

Avolio, B. J. (2007). Promoting more integrative strategies for leadership theory-building. American Psychologist, 62(1), 25-33.

Ayub, S. H., Manaf, A. N., \& Hamazah, M. R. (2014). Leadership : Communicating strategically in the 21st Century. Procedia Social and Behavioral Sciences, 155, 502-506. https://doi.org/10.1016/j.sbspro.2014.10.330.

Bass, B. M. (2000). The future of leadership in learning organizations. Journal of Leadership Studies, 7(3), 18-40. https://doi. org/10.1177/107179190000700302

Bass, B. M., \& Stogdill, R. M. (1990). Bass \& Stogdill's handbook of leadership: Flora Theory, research, and managerial applications. Free Press.

Boies, K., Fiset, J., \& Gill, H. (2015). Communication and trust are key: Unlocking the relationship between leadership and team performance and creativity. The Leadership Quarterly, 26(6), 1080-1094. https://doi.org/10.1016/j.leaqua.2015. 07.007

Brown, C., Czerniewicz, L., Mayiesela, T., \& Huang, C.-W. (2016). A practice based approach to theorising digital education leadership. http://dspace.col.org/bitstream/handle/11599/2542/PDF

Buabeng-Andoh, C. (2012). Factors influencing teachers'adoption and integration of information and communication technology into teaching : A review of the literature. International Journal of Education and Development Using Information and Communication Technology, 8(1), 136-155.

Cox, D. D., \& McLeod, S. (2014). Social media marketing and communications strategies for school superintendents. Journal of Educational Administration, 52(6), 850-868. https://doi.org/10.1108/JEA-11-2012-0117

Creswell, J. W. (2018). Qualitative inquiry and research design: Choosing among five approaches. SAGE Publications (fourth Ed). https://doi.org/10.1111/1467-9299.00177

Graen, G., Rowold, J., \& Heinitz, K. (2010). Issues in operationalizing and comparing leadership constructs. The Leadership Quarterly, 21(3), 563-575.

Harris, A. (2009). Distributed leadership: Different perspectives. Studies in educational leadership (Vol. 7). London: Springer.

Haythornthwaite, C., \& Kendall, L. (2010). Internet and community. American Behavioral Scientist, 53(8), 1083-1094. https:// doi.org/10.1177/0002764209356242

Ibrahim, M. Y. (2015). Model of virtual leadership, intra-team communication and job performance among school leaders in malaysia. Procedia - Social and Behavioral Sciences, 186, 674-680. https://doi.org/10.1016/j.sbspro.2015.04.126

Jameson, J. (2013). E-Leadership in higher education: The fifth "age" of educational technology research. British Journal of Educational Technology, 44(6), 889-915.

Leithwood, K., Day, C., Sammons, P., Harris, A., \& Hopkins, D. (2006). Successful school leadership what it is and how it influences pupil learning. Nottingham, UK.

Lieve, V. den B., Malin, C., \& Barbara, G. (2010). Learning, Innovation and ICT: Lessons learned by the ICT cluster Education \& Training 2010 programme. Education and Culture of the European Commission. Retrieved from https://erte.dge. mec.pt/sites/default/files/Recursos/Estudos/key_lessons_ict_cluster_final_report.pdf

Littlejohn, S. W., \& Foss, K. A. (2010). Theories of human communication.California, USA: Waveland Press.

Malaysian Communications and Multimedia Commission. (2017). Internet Survey Users 2017. Retrieved from https:// www.mcmc.gov.my/skmmgovmy/media/General/pdf/MCMC-Internet-Users-Survey-2017.pdf

Mason, M. (2014). Complexity theory in education governance: initiating and sustaining systemic change. Governing Complex Education Systems (GCES): Understanding complexity: The future of education governance, Ministry of Education and Research Oslo, Norway. http://repository.lib.eduhk.hk/jspui/handle/2260.2/19414

Mason, M. (2008). What is complexity theory and what are its implications for educational change? Educational Philosophy and Theory, 40(1), 35-49. https://doi.org/10.1111/j.1469-5812.2007.00413.x

McCleskey, J. A. (2014). Situational, transformational, and transactional leadership and leadership development. Journal of Business Studies Quarterly, 5(4), 117.

Men, L. R. (2015). The internal communication role of the chief executive officer: Communication channels, style, and effectiveness. Public Relations Review, 41(4), 461-471. https://doi.org/10.1016/.jpubrev.2015.06.021

Merriam, S. B., \& Tisdell, E. J. (2016). Qualitative research: A guide to design and implementation (4th ed.). Jossey-Bass.

Ministry of Education Malaysia (2013). Malaysian Education Blueprint 2013- 2025.Retrieved from https://www.moe.gov. my/menumedia/media-cetak/penerbitan/dasar/1207-malaysia-education-blueprint-2013-2025/file.

Norman, M., \& Hashim, R. A. (2016). Contextual leadership practices: The case of a successful school principal in Malaysia. Educational Management Administration \& Leadership. https://doi.org/10.1177/1741143216665840

Outvorst, F., Visker, C.., \& Waal, B. (2017). Digital leadership: The consequences of organizing and working in a digital society. In Proceedings of the European Conference On Management, Leadership \& Governance (ICMLG 2017), Johannesburg (pp. 43-471).

Patton, M. Q. (2002). Qualitative research and evaluation methods (3rd ed.). Sage.

Perera, C. J., Adams, D., \& Muniandy, V. (2016). Principal preparation and professional development in Malaysia: Exploring key influences and current practice. In A. Harris \& M. Jones (Eds.), Leading futures: global perspectives on educational leadership (pp. 125-137). SAGE Press.

Ribble, M., \& Miller, T. N. (2013). Educational leadership in an online world: connecting students to technology responsibly, safely, and ethically. Journal of Asynchronous Learning Network, 17(1), 137-145. 
Richardson, J. W., Flora, K., \& Bathon, J. (2013). Fostering a school technology vision in school leaders. NCPEA International Journal of Educational Leadership Preparation, 8(1), 144-161.

Sheninger, E. (2014). Digital leadership: Changing paradigms for changing times. Corwin Press.

Uhl-Bien, M., Marion, R., \& McKelvey, B. (2007). Complexity leadership theory: Shifting leadership from the industrial age to the knowledge era. Leadership Quarterly, 18(4), 298-318.

Wang, V. C., \& Torrisi-Steele, G. (2017). Digital leadership in the new century. In Encyclopedia of strategic leadership and management (pp. 143-159). IGI Global.

Yin, R. K. (2011). Qualitative research from start to finish. The Guilford Press.

Yu, C., \& Prince, D. L. (2016). Aspiring school administrators' perceived ability to meet technology standards and technological needs for professional development. Journal of Research on Technology in Education, 48(4), 239-257.

Zhong, L. (2016). The Effectiveness of Digital Leadership at K-12 Schools in Mississippi Regarding Communication and Collaboration During CCRS Implementation. The University of Southern Mississippi.

\section{Publisher's Note}

Springer Nature remains neutral with regard to jurisdictional claims in published maps and institutional affiliations.

\section{Submit your manuscript to a SpringerOpen ${ }^{\circ}$ journal and benefit from:}

- Convenient online submission

- Rigorous peer review

- Open access: articles freely available online

- High visibility within the field

- Retaining the copyright to your article

Submit your next manuscript at $>$ springeropen.com 